\title{
Why the European Commission is Wrong to Push for a European Financial Transactions Tax
}

\section{Photis Lysandrou}

Research Fellow at the Political Economy Research Center, City University (CITYPERC) and Associate Professor of Economics at the School of Oriental and African Studies.

Short term trading is necessary to the functioning of European commercial banks and asset management firms. Given the importance of these institutions, it follows that a tax that restrains all such trading would undermine the European financial system's ability to service the real economy. It is better to allow financial institutions to perform their functions unhindered and tax any excessive profits made out of the performance of those functions.

Key words: European Commission; financial transactions tax; financial activities tax

\section{Introduction}

In late September, 2011, the European Commission proposed that a Financial Transactions Tax (FTT) be the preferred method by which European governments should tax their financial systems to recoup some of the losses incurred in the financial crisis of 2007-08. ${ }^{1}$ Although the Commission's staff also studied the merits of a Financial Activities Tax (FAT), which is a tax on the profits and wages of financial institutions rather than a tax on transactions in the financial markets, the EC finally decided in favour of the FTT on the grounds that it would both generate revenue for governments and help to stabilize the financial markets by curbing trading volumes. In making this proposal, the Commission effectively made clear its endorsement of the premise that as all short term trading is purely speculative it can only be central to the functions of institutions that are peripheral to the financial system and only peripheral to the functions of institutions that are central to the system.

This paper contests the above premise. While it accepts that some short term trading in the money and capital markets is speculative and thus potentially destabilizing, it also argues that other parts of short term trading are necessary to the day-to-day activities of commercial banks and asset management firms. In view of the importance of commercial banks and institutional asset managers to the European financial system, it follows that the introduction of a European FTT that indiscriminately restrains all short term trading would bring about a result that is the very opposite of that intended by the Commission. Rather than enhance the ability of the European financial system to service the real economy in a stable and cost efficient manner, the proposed tax would on the contrary severely undermine that ability. The conclusion drawn here is that it would be far better to allow important financial institutions to perform their functions unhindered and then tax any excessive profits made out of the performance of those functions.

The structure of this paper is as follows. Section two reviews the reasons behind the Commission's choice of a transactions tax. Section three focuses on the effects of a capital market FTT on European asset managers. Section four focuses on the effects of a money market FTT on European banks. Section five looks at some implications. Section six concludes.

\section{The Rationale for a European FTT}

As a result of the extensive damage to domestic economies and public finances wrought by the financial crisis, 
a number of European governments introduced special tax measures aimed at repairing the state's fiscal position and making the financial sector bear some of the costs of the crisis. Fearing that the lack of coordination of these national measures could fragment the European internal market for financial services, the European Council and the European Parliament called upon the European Commission to prepare a proposal for a common approach to taxing the financial sector ${ }^{2}$. In response to these calls the Commission authorised several studies that compared the relative advantages of two major types of tax instrument, the Financial Activities Tax that would be levied on the value added by financial institutions and the Financial Transactions Tax that would target trading activity in the financial markets ${ }^{3}$. Although at one point it looked as though the FAT would be favoured ${ }^{4}$, the Commission finally decided in favour of the FTT on the grounds that not only would this tax be marginally more effective in achieving the revenue raising objective but also that it alone would be able to achieve the second major objective of "limiting undesirable behaviour and thus stabilizing markets" (EC 2011b, 3). Central to this conclusion is the identification of 'undesirable behaviour' with 'trading behaviour': while the FTT would have a directly negative impact on trading volumes by raising the cost of financial transactions, the FAT would have no equivalent impact. As the Commission's Impact Assessment states: „The FAT does not have a direct impact on the trading behaviour in financial markets" (EC 2011, 6)

The controversy that has followed the proposal for a European financial transactions tax has centred on two broad issues, feasibility and desirability. The strong objections to the FTT voiced by some European governments have served to highlight the risk that if Europe proceeds with the FTT without any global agreement to implement the tax a substantial proportion of financial trades currently conducted in Europe will be redirected to untaxed jurisdictions and markets. In an earlier working paper on financial sector taxation the Commission's staff conceded the point that if a transactions tax ,is not introduced on the global scale it has the potential to divert economic activity ..therefore... the tax has to be as comprehensive as possible" (EC 2010). Although the required level of agreement for a global FTT has yet to materialise, the Commission has nevertheless decided to change its position and press ahead with a European FTT on the grounds that if a transactions tax is the best possible method of taxing the financial sector in the post-crisis period then everything should be done to win international agreement for the tax.

The Commission is right to rest its case for the FTT on a matter of principle rather than on considerations of expediency. However, its argument raises the question of whether the FTT is in fact the most effective method of taxing the financial sector. Recall the Commission's claim that the FTT's advantage over the FAT is that it can achieve two objectives simultaneously: market stabilisation in addition to revenue generation. The central idea behind this claim is that there is a positive correlation between trading volume and price volatility: by reducing the volume of short term trading the FTT can help to reduce price volatility, which must in turn help to promote the informational efficiency of the financial markets. As the Commission's Impact Assessment study asserts: „The aspects of dealing with risk and behavioural aspects of the FTT relate to the possibility of the FTT to curb speculation, noise trading and technical trade, and to decrease market volatility" (EC 2010, 10). The problem with this assertion is that it does not receive unambiguous support either from the empirical evidence or from economic theory. As concerns the former, some studies show a close correlation between trading volume and price volatility, but others show no such correlation. As concerns the latter, while some economists argue that excessive trading can cause price volatility, others put the contrary argument that too little trading can cause prices to be more volatile than usual because of 'market thinning's.

In sum, the Commission's case for the FTT is not a powerful, and certainly not a unanimous one. However, if the Commission persists with this tax policy this is in large part because the standard arguments against the FTT also lack sufficient power ${ }^{6}$. Whatever the differences between the critics and supporters of the FTT regarding the merits of speculative trading, both sides in the debate essentially agree that most short term trades are speculative in nature. This consensus explains why all current assessments of the costs and benefits of the FTT only focus on its impact on financial market stability that is transmitted via its impact on financial prices while largely ignoring the impact on stability that is transmitted via its impact on financial institutions, or through dampened liquidity. This paper takes a different position. While it may be that a significant amount of short term trading is speculative, it is also the case that an equally significant amount has nothing to do with speculation and instead forms an indispensable part of the daily operations of major institutions such as pension and mutual funds on the one hand and the commercial banks on the other. It thus follows that any complete assessment of the costs and benefits of the FTT must also focus on its impact on these institutions. 


\section{Capital market taxes and the asset management function.}

When one looks at recent trends in equity market trading one can understand why the Commission has singled out high frequency trading (HFT) for special attention when making its case for the FTT. As can be seen in figure 1, while trading volumes in the world's largest equity markets grew steadily between the early 1990s and the mid2000 s, there was a sharp upward spike in volumes after this point before they again fell after the financial crisis. There is no doubt that this upward spike was in large part caused by the advent of high frequency trading. Although the electronification of securities trading dates from the early 1970 s with the formation of NASDAQ in the US, it was not until the 1990s that securities trading in the EU area began to grow in fully automated exchanges and it is not until the mid-2000s that HFT became established as a significant proportion of automated trading (Gomber et.al., 2011).

Two concessions are made here. First, that HFT is purely speculative in nature as can be seen from the list of its defining characteristics presented in the bottom right box in figure 2, and, second, that the imposition of the FTT will certainly help to curb HFT. However, we also ask two questions that are never raised by the Commission. The first is what is the percentage share of high frequency trading out of all automated trading? The commission's proposal for the FTT gives the impression that HFT is the dominant form of automated trading, but while this may be true in the US where current estimates are that HFT account for 50 to $55 \%$ of all automated trading. The remainder is comprised of algorithmic trad- ing. The estimates for the EU are that algorithmic trading continues to account for the majority share of automated trading, 70 to $75 \%$ (Valiante and Lanoo, 2011, p.36).

Figure 2 Algorithmic versus High Frequency Trading

\begin{tabular}{|l|}
\hline 1) Pre-designed trading decisions \\
2) Used by professional traders \\
3) Observing market data in real-time \\
4) Automated order submission \\
5) Automated order management \\
6) Without human intervention \\
7) Use of direct markets access \\
\hline
\end{tabular}

\begin{tabular}{|l|l|}
\hline \multicolumn{1}{|c|}{ Specific for AT excl. HFT } & \multicolumn{1}{c|}{ Specific for HFT } \\
1) Agent trading & 1) Very high number of orders \\
2) Minimise market impact (large & 2) Rapid order cancellation \\
orders) & 3) Proprietary trading \\
3) Goal is to achieve a particular & 4) Profit from buying and selling \\
benchmark & 5) No signification position at \\
4) Holding periods: days/weeks/ & day's end \\
months & 6) Very short holding periods \\
5) Working order through time and & 7) Extracting very low margins \\
across markets & per trade \\
& 8) Low latency requirement \\
& 9) Use of co-location \\
& 10) Focus on high liquid instruments \\
\hline
\end{tabular}

Source: Gomber et.al. (2011)

The second question is who are the agents engaging in algorithmic and high frequency trading respectively? The fact that the Commission singles out HFT for special mention when discussing automated trading may give the impression that its other important subset, algorithmic trading, is not all that different from HFT either in terms

Figure 1 Share Trading \% of Domestic Market Capitalisation

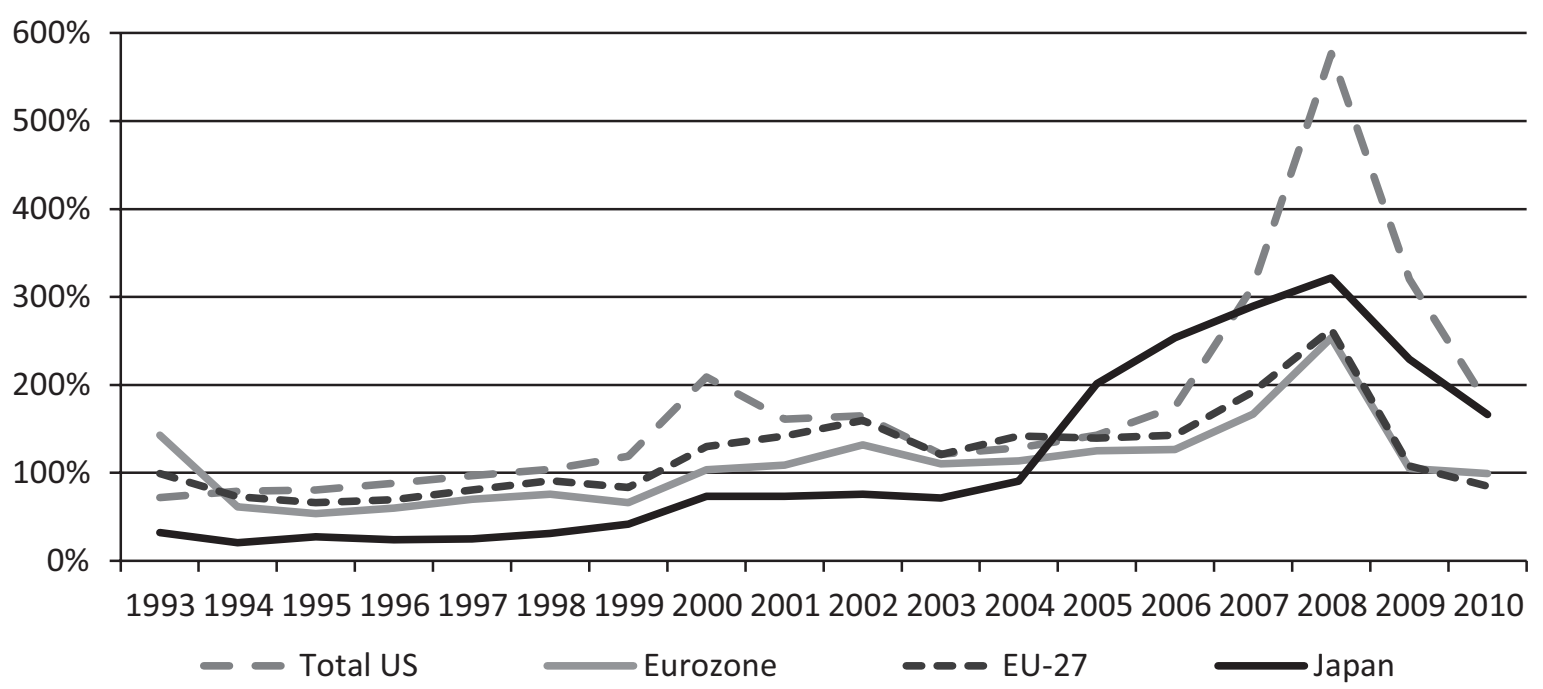

Source: ECMI (2011) 
of the trading players involved or in terms of the central trading purpose. This impression is wrong. While algorithmic and HFT have several common characteristics by virtue of being subsets of automated trading (as shown in the top half of figure 2) the differences between these two subsets are more important because they relate to two contrasting types of financial function performed by two contrasting types of financial institution. Where HFT is speculative trading conducted primarily by hedge funds and other proprietary trading vehicles, algorithmic trading is portfolio trading conducted by institutional asset managers and in particular by mutual funds. As the latter have a fairly long history one may well wonder why it is relatively recently that they have begun to use algorithmic forms of trading on so comprehensive a scale. The answer lies in the new pressures on fund managers as much as in technological advances. Algorithmic trading, like HFT, is a recent phenomenon, but while new computerised techniques have enabled its development, structural changes in the fund management industry have been its chief motivation.

It is a general rule that whenever an industry grows in scale there is a corresponding shift towards more standardized forms of provision in order to accommodate increased demands while containing costs. The fund management industry is no exception. In place of the broad based and discretionally managed portfolio that was previously the norm, what is now more typical is the narrow portfolio managed to a particular investment target. Indexation strategies are at the heart of the new approach to fund management, for it is by taking a market or sub-market index as a benchmark, while varying tracking error limits, that a portfolio can assume the form of a standardized product carrying a specified set of riskreturn characteristics. The advantages arising out of the separation and narrowing of portfolios are two-fold: on the one hand there is better 'risk-conservation' as each additional unit of risk is matched more closely to a corresponding additional unit of return; on the other hand there is a more accurate measure of managerial performance because it may be easier to assess this performance and avoid confusing high returns based on risk from those which reflect superior knowledge and judgement.

The rise in algorithmic trading closely ties in with the increasing standardization of fund management because it helps managers to resolve a trading dilemma that has become particularly acute with this development. On the one hand trading for portfolio balancing purposes has greatly intensified: where trading was previously an exogenous activity in that while required to set up a portfolio it was not subsequently necessary to the latter's maintenance, trading has now become an endogenous activity, necessary for keeping a portfolio to a specified investment target. Algorithmic trading facilitates this need for constant portfolio rebalancing by helping to speed up the execution of institutional orders. On the other hand, trading can be very costly even while it is unavoidable: the trading of large institutional orders can cause price disturbances that then create opportunities for poachers to front-run the orders and thereby raise trading costs. Institutional investors have traditionally sought to minimize the price impact of their trades by slicing large 'parent' orders into many smaller 'child' orders that are then fed through the exchanges. Algorithmic trading facilitates this price impact minimization by helping managers to determine how best to slice large orders into smaller orders and where best to execute these orders.

In sum, algorithmic trading is 'portfolio-serving', trading to keep a portfolio to its benchmark, in contrast to high frequency trading that is 'self-serving', trading purely aimed at making a profit. However, a further important thing to note here is that HFT is not only fundamentally antithetical to algorithmic trading but is also parasitic on the latter. Where institutional asset managers typically engage in algorithmic trading to avoid price volatility and thus avoid giving profitable opportunities to poachers, the hedge funds and other speculative vehicles on the contrary are the poachers and engage in HFT precisely in order to feed off any price volatility caused by institutional trading. This is why HFT concentrates on large cap liquid securities, those that dominate the indexes used by the mutual and pension funds as their benchmarks, and this is why hedge funds place their computers in close proximity to those used by the mutual funds in the major trading venues (a practice known as 'co-location').

The upshot of the above discussion is that the imposition of the FTT in the secondary equity markets would be self defeating. The tax would certainly succeed in curbing HFT but in doing so it will also harm algorithmic trading on which HFT is parasitic. To use an analogy, it is like giving a pet dog that has fleas so strong a medicine that it also kills the dog: effective for the fleas but pointless overall. It could of course be argued that this negative side effect may be a price worth paying if HFT volumes can be significantly reduced. However, this argument would only hold if the current trends in portfolio management that give rise to algorithmic trading as an indispensable activity were themselves not an irreversible aspect of the contemporary European financial landscape. The reality is that they are. The greater the pressures on government finances, which have been further severely stretched by the financial crisis, the greater are the government incentives to force increasing numbers of middle and higher 
income households to make their own arrangements for supplementary pension and other welfare provision. The greater the drive towards welfare arrangements focussed on protecting lower-income groups and moving them towards median positions, the greater will be the corresponding demands made upon the asset management industry and the greater therefore is this industry's drive towards standardization as a means of coping with these demands. Thus algorithmic trading is set to continue to expand in importance given the ongoing shift towards the standardization asset management and given the endogeneity of trading to portfolios that track market indexes.

\section{Money market taxes and the banking function.}

Trading volumes in the money markets, like those in the capital markets, have in recent decades grown at rates far in excess of what can be meaningfully explained in terms of real sector activities for which reason the Commission has proposed to bring all money market instruments under the scope of the FTT. In our view, this proposal is wrong because the growth of money market trading has principally been powered by inter-bank transactions that have been linked to the pressures on the banking function emanating from the securities markets. The rapid development and international integration of the money markets is a direct consequence of the increased role of institutional investors and the accompanying shift away from classical bank intermediation towards greater use of the security markets. This shift is not going to be reversed. On the one hand such a move would fragment financial systems at a time when economic systems are increasingly integrated. On the other hand, tighter regulatory constraints on banks will require them to reduce their use of leverage and this in turn will mean that they hold fewer long-term assets and make more use of securitisation. The higher capital ratios to which the banking system is moving are already making it more advantageous to distribute loans via the security markets and disadvantageous to hold them to maturity. Thus large banks and security markets will continue to function in symbiosis, with the banks performing many functions tied to the security markets and especially supplying the transactions balances needed by the agents trading securities. The money market is a key point of tension in this function because of "the paradox of disintermediation " : money is less and less held as an asset but is increasingly needed as a means of exchange to support the growing volume of security trading. The money market resolves the paradox by accelerating interbank transactions to an astonishing degree: huge sums are transferred from bank to bank at enormous speed and at very low cost.

Inter-bank transactions essentially take two forms: unsecured (i.e no use of backing collateral) and secured (i.e use of backing collateral). As unsecured borrowing involves more risk to lenders, this is typically confined to the very shortest of time spans. This said, it should be noted that after the recent financial crisis where the trust between banks has become more fragile, the proportion of unsecured borrowing and lending activity has fallen in favour of securitised forms of activity (see figure 3). The principal form of securitised borrowing is the repo: the sale of collateral such as government bonds for cash, and the repurchase of these same bonds with cash. Now it is

Figure 3 Average daily turnover in various money market segments (index: unsecured transaction volume in $2002=100$ )

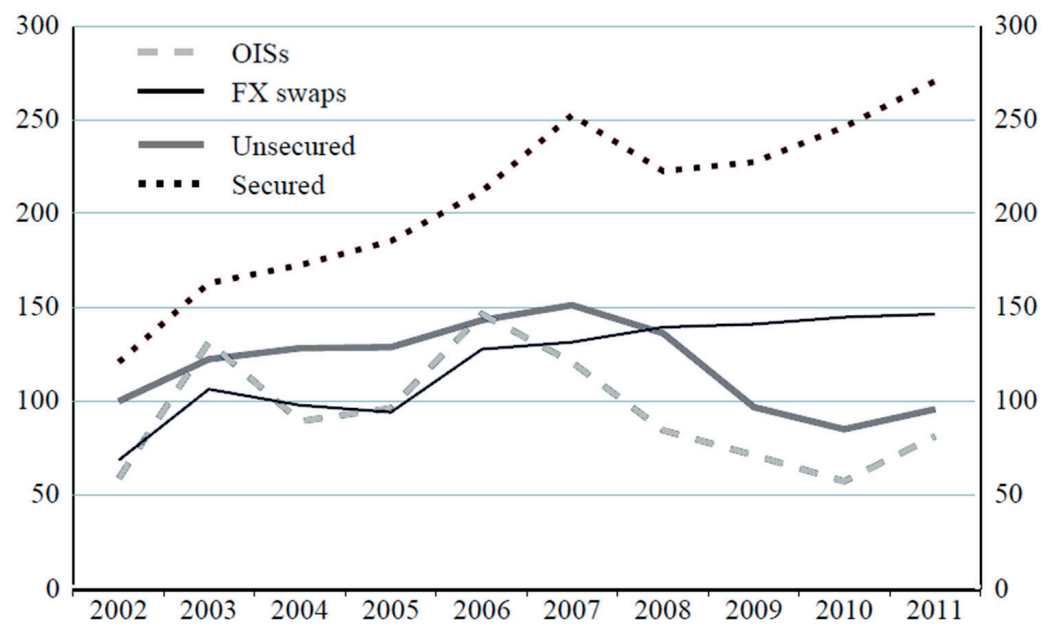


proposed to apply the FTT to repos on the grounds that a) they are 'transactions' inasmuch as they involve the sale and purchase of securities and b) these transactions are typically short term and hence presumably speculative in nature. This is illogical. Not only did the inter-bank money market break down during the crisis but there also subsequently occurred an even deeper and more comprehensive breakdown in Europe as a consequence of the sovereign debt crisis. This impairment of the money market can only be aggravated by the proposed tax on repo transactions. The suggested rate of 10 basis points is much greater than the interest charged on most repos because they are short-run credits meant only to finance rapidly executed portfolio changes. In consequence the inter-bank market would be seriously attenuated, and security markets affected by the reduced availability and increased cost of transactions balances. Since, as was argued in section 3, much of the trading in securities markets is economically functional and since increased constraints on the banks will make economies more dependent on these markets, the application of the FTT to inter-bank loans is likely to be economically damaging.

The illogicality in the Commission's position is further compounded by the fact that it does not intend to extend the FTT to cover foreign exchange swaps. These foreign exchange (FX) instruments, which combine spot FX transactions with outright forward transactions, account for about $50 \%$ of all daily FX trading that is now in the region of $\$ 5$ trillion. The major users of FX swaps are the dealing banks, and one main motivation is that these instruments represent a cheap, because collateralised, form of borrowing a foreign currency; thus when a eurozone bank wants to borrow dollars short term, it is cheaper to do so through an FX swap, selling euros for dollars in a spot transaction and repurchasing the euros with dollars in the reverse forward transaction. However, a more important reason why banks use FX swaps is that these serve as an alternative type of repo: a Eurozone bank wanting to borrow euros can either engage in a straightforward repo transaction - using government bonds as collateral - or in an FX swap - selling dollars for euros and then repurchasing the dollars with euros, the point here being that dollars not government securities act as the collateral.

Now there is already a perceived tendency to supplement ordinary repo transactions with FX swaps on the part of eurozone banks because of the increasing shortage of good quality government bonds to serve as collateral. Following the introduction of euro, the world's investors did for a time treat all Eurozone government bonds as a more or less homogenous class because of the elimination of currency risk, a development that became manifest in the narrowing of government yield spreads. With the advent of the sovereign debt crisis and the consequent rise in credit risk considerations in the minds of bond investors these yield spreads have again widened as the Eurozone government bond market again fragmented into heterogeneous groups. Among the best quality government bonds are those of the German government but these are in short supply due to the heavy pressure of demand from investors seeking a safe haven (according to a recent survey on the European repo market (ICMA, 2012), the share of German government bonds as collateral in repo transactions fell from $22.4 \%$ in June 2011 to $20.7 \%$ in June 2012). As a result, the Eurozone banks have had to find alternative assets to use as collateral, including the US dollar. A measure of the extent to which these banks rely on FX swaps less for currency related than for repo type borrowings is indicated by the unusually high ratio of inter-dealer FX transactions in the euro area: 64\% (67\% for FX swaps) as compared with a rest of the world average of 39\% (ECB, 2010).

Given that the Commission proposes to tax repos but not FX swaps, the use of these instruments as alternative credit transactions to the repo will increase further, thus boosting the already large FX swap daily volume. This is ironic because the original Tobin tax that gave inspiration to all subsequent financial transaction tax proposals was specifically directed at FX transactions but here we have a situation where the Commission's imposition of the FTT on ordinary repos will help to swell FX transactions by conferring a tax advantage on them. It was because they recognised this anomaly that members of the European Parliament voted in May 2012 to bring 'currency spot transactions' under the scope of the FTT ${ }^{8}$. However, the fact that the European Parliament did not vote to also bring FX swaps (or outright forward currency transactions) under the scope of the FTT only served to further highlight the inconsistency in the Commission's proposal to tax one form of collateral (repos) but not another (US dollars). This inconsistency is the most worrying feature of the FTT and is likely to make it unworkable as an EU strategy because it would both further undermine the liquidity of euro-denominated bond markets and make the liquidity of the European banking system completely dependent on credit conditions in the US.

A final important observation to make here is that the weakening of the inter-bank money market also has serious implications for the implementation of monetary policy. Monetary policy today relies on the existence of an integrated money market, which gives the central bank's actions in that market macroeconomic significance. This is one reason the ECB is trying to end the exclusion of banking systems in the periphery from the money mar- 
ket - until it does so the transmission of monetary policy decisions will be partial and uneven. Indeed, if integral money markets cannot be restored then monetary policy will be ineffective. In the first instance the central bank will have to engage in separate negotiations with each fraction of the divided market and have to judge what the effect of this multiplicity of individual interventions will be. Furthermore, the efficacy of monetary policy depends on the existence of an elastic supply of credit; monetary policy affects the terms on which that credit is issued. If banks and other financial corporations find that credit is not available, then they will accumulate big money balances to reduce the risk of not being able to carry out their desired transactions. Once financial agents have insulated themselves from the credit system in this way they have also insulated themselves against central bank actions - since they are not making use of the money market, changes in money market conditions have no clear impact on their own strategies.

\section{Policy Implications}

As the economic rationale for the FTT is extremely weak, it follows that the rationale for the tax has ultimately to rest on political considerations. The key political problem is the conflict between strong popular demands for a tax on banks and the equally strong opposition to any form of bank taxation mounted by the banks themselves. The Commission appears to have decided that the FTT represents the most judicious way of resolving this conflict because on the one side it has become fixed in popular opinion through its association with the Tobin tax and because on the other this tax represents less of a threat to banks' interests as compared with a FAT. This is not only because the FAT is a direct tax on bank profits unlike the FTT that taxes trading activities that only form part of the source of profits. It is also because the FAT can be focussed on specific institutions unlike the FTT that indiscriminately affects all types of institution engaging in the transactions that are subject to this tax. The banks, as explained, may be the institutions most affected by a FTT in the money markets, but in the capital markets where it is the large fund managers who do most of the trading it is these non-bank institutions that will be most affected. In the end, the banks prefer the FTT as the least threatening form of taxation because they know that it will be eventually repealed not only because of the refusal of some national authorities to implement the tax but also because of the strong objections to it that are raised by the European fund management industry on account of its negative impact on portfolio rebalancing transactions. Aside from this point, there are two further reasons why the mutual fund and insurance company sectors will raise strong objections to the FTT.

The first is that the fund management sector neither caused the financial crisis nor benefitted from any of the government financial assistance that was given in the aftermath of the crisis. While certain non-bank financial institutions, notably the hedge funds, may have been to some extent complicit in precipitating the subprime crisis that subsequently mutated into a full blown financial crisis, the pension and mutual fund sector could reasonably argue that their role in that initial crisis was more that of the victim than that of the perpetrator. The second reason for this sector's opposition to the FTT is that short term trading was not a root cause of the last financial crisis and thus its curtailment will not necessarily help to prevent a future financial crisis. The Commission argues that the FTT would „complement regulatory measures aimed at avoiding future crises" $(2011 \mathrm{a}, 2)$ but the fact is that trading played no major role in the last financial crisis. The products at the epicentre of the initial subprime phase of the crisis were collateralised debt obligations (CDOs), credit instruments that were so complex and opaque in structure that they could not be easily traded and priced according to any market standard. Indeed, it was precisely because they were difficult to price and consequently difficult to trade that these products helped to precipitate the breakdown in trust between banks that in turn caused the money and interbank markets to freeze up completely in August, 2007. In this second phase of the financial crisis, trading was again to play no major role. Rather, that role belonged to the huge asset-liability mismatches of the bank owned conduits and structured investment vehicles (SIVs). Thus while it was indeed the case that the 'particularly risky behaviour' on the part of the banks and other segments of the financial markets was a root cause of the financial crisis, that risky behaviour had less to do with financial trading than with excessive leverage and capital inadequacy.

The above observations mean that the Commission's logic behind its choice of the FTT as the preferred means of taxing the European financial sector can be stood on its head. If the intention behind a European financial tax is not only to force financial institutions to bear some of the costs of the last financial crisis but also to force changes in their behaviour so as to prevent a future financial crisis then it is not the FTT but the FAT that is superior. The explanation is clear. If it is the prospect of distributing huge financial profits in the form of generous salaries and bonuses that is the chief motivation for excessive leverage and other types of excessive risk taking in the financial sector, then it must follow that the most effective way of 
dealing with this problem is to tax financial profits before they can be distributed.

\section{Conclusion}

There is a widely held view that as long as the banks are taxed to help repay some of the vast sums of taxpayers' money they have absorbed since the crisis, it does not really matter what type of tax policy is applied. This paper has argued that it does matter enormously what sort of tax or revenue arrangements are applied to finance. Apply the wrong tax and the objective of getting the banking sector to shoulder its part of the post-crisis financial burden will ultimately fail. While the analysis developed here suggests that the challenges of seeking some share in the wealth created and transmitted through financial markets (especially in the wake of the large amounts of national wealth pledged to bail out banks and some financial institutions) is not adequately captured by the current focus, the better tax is the financial activities tax because the better strategy for raising public revenues is to tax the immense private fortunes that have been accumulated by the very same abuse of financial and corporate power that has rendered democratic governments insolvent. It is hard to deny that a FAT would perform this necessary redistributive function far more effectively than a FTT.

\section{Notes}

1. Council directive on a common system of financial transaction tax and amending Directive 2008/7/EC; Commission Staff Working Paper (28.9.2011); Executive Summary of the Impact Assessment (accompanying Directive on a common system of financial transaction tax (28.9.2011).

2. Council of the European Union, 17 June, 2010; Resolution of the European Parliament, March 10, 2010.

3. EU Commission staff working document, Innovative Financing at a Global Level, (1 April, 2010a); EU Commission staff working document, Taxation of the Financial Sector, (7 October, 2010b).

4. See in particular the EU Commission staff working document, Innovative Financing at a Global Level.

5. See e.g. the report to the European Parliament by Kern Alexander et.al. (European Parliament, 2010, p31).

6. See IMF, 2010, pp.17-20, for a list of objections to the FTT. For a critique of each of these objections to the FTT see Schulmeister, 2011.
7. Grahl and Lysandrou, 2003.

8. European Parliament, Legislative proposal to implement enhanced cooperation in the area of financial transactions tax (FTT), February, 2013.

\section{References}

European Central Bank 2010, BIS Triennial Survey 2010 -Euro Area Data, Frankfurt am Main.

European Central Bank 2011, Euro Money Market Survey, September, Frankfurt am Main.

European Capital Markets Institute 2011, Statistical Package 2011, Brussels.

European Commission 2010, Innovative Financing at a Global Level, Brussels.

European Commission 2011a, Council directive on a common system of financial transaction tax and amending Directive 2008/7/EC, Commission Staff Working Paper (28.9.2011), Brussels.

European Commission 2011b, Executive Summary of the Impact Assessment (accompanying Directive on a common system of financial transaction tax) (28.9.2011), Brussels.

European Parliament 2010, Crisis Management, Burden-sharing and Solidarity Mechanisms in the EU, Strassburg.

European Parliament 2013, Legislative proposal to implement enhanced cooperation in the area of financial transactions tax (FTT), Strassburg.

Gomber, P; Arndt, B; Lutat, M \& Uhle, T 2011, High Frequency Trading, Goethe University, Deutsche Borse Discussion Paper, March.

Grahl, J \& Lysandrou, P 2003, 'Sand in the wheels or spanner in the works: The Tobin tax and global finance', Cambridge Journal of Economics, vol.27, No.4, pp. 597-621.

Grahl, J \& Lysandrou, P 2006, 'Capital market trading volume: An overview and some preliminary conclusions', Cambridge Journal of Economics, vol.30, no.6, pp. 955-979.

International Capital Market Association 2012, European Repo Market Survey, June.

International Monetary Fund 2010, A fair and substantial contribution by the financial sector, Final Report for the G-20, June.

Lysandrou, P 2012, 'The Primacy of Hedge Funds in the Subprime Crisis', Journal of Post Keynesian Economics, vol. 34, no. 2, 225-253.

Schulmeister, S 2011, Implementation of a General Financial Transactions Tax, Austrian institute of Economic Research, project No. 2911.

Valiante, D \& Lannoo, K 2011, MiFID 2.0: Casting New Light on Europe's Capital Markets, Centre for European Policy Studies.

Varian, H D 2000, Variant in Economic Theory: Selected Work of Hal R Varian, Cheltenham: Edward Elgar.

Vella, J; Fuest, C \& Schmidt-Eisenlohr, T 2011, The EU Commission's proposal for a financial transaction tax, British Tax Review, No. 6. 